\title{
MODELING OF THE TRAJECTORY OF THE LEVEL FLUCTUATIONS IN LAKE NAROCH
}

\author{
Ivan Kirvel ${ }^{1}$, Alexander VolchaK ${ }^{2}$, Sergey ParfomuK ${ }^{2}$ \\ ${ }^{1}$ Institute of Geography and Regional Studies, Pomeranian University in Słupsk, Poland \\ ${ }^{2}$ Computer Science and Applied Mathematics, Brest State Technical University, Brest, Belarus
}

Manuscript received: June 8, 2015

Revised version: February 11, 2016

Kirvel I., VolchaK A., Parfomuk S., 2016. Modeling of the trajectory of the level fluctuations in Lake Naroch. Quaestiones Geographicae 35(1), Bogucki Wydawnictwo Naukowe, Poznań, pp. 57-62, 7 figs.

AвstRAct: As a result of the conducted investigations of the level fluctuations in Lake Naroch the initial data are divided into 3 components: a polynomial regression that makes it possible to find out an independent on time Law of trajectory, a periodic component of sinusoidal type and a residual sequence of independent random quantities. Modeling of the trajectory fluctuations is based on the deterministic part, consisting of the regression of the 8th order and periodic component, and also the random part, consisting of independent equally distributed quantities. Using this model it can be modeled the trajectory of the level fluctuations in Lake Naroch. The modeled trajectory by 200 years long demonstrated the probability of exceeding of maximum annual level, equal 1 per cent.

KEY WORDS: lake level changes, modelling, trajectory, recent past, Lake Naroch, Belarus

Corresponding author: Ivan Kirvel (kirviel@yandex.ru)

\section{Introduction}

Lake Naroch is the largest Lake in Belarus. It is situated in the north-west part of the Belarus near the Lithuanian border. The main direction of rational use of Lake Naroch is more productive fish breeding and recreation activities. But it must be said that the development of health resorts, the increase in the number of holiday makers and tourists create a threat to the preservation of the mesotrophic level of the Lake system. The data of long studies point to the stability of the Naroch ecological system to anthropogenic influence on the one hand, and on the other hand some signs of anthropogenic eutrophication could be observed. Land cultivation, reclaiming of marshy areas, widening of populated area have some influence on the Lake. A significant change in the Lake level threatens massive ecological and economic disaster. In recent years, the amplitude of fluctuations of the Lake level increased, so that there is the risk of shallowing or exceeding the maximum level.

The problem arises: based on the statistical properties of the series of lake level, calculate the probability of reaching extremely low or high level, and using an adequate stochastic model. The aim of this work is modeling of possible fluctuations of the average annual lake levels. 


\section{Study area}

Lake Naroch is situated in the basin of the river Naroch (outflows from the Lake), $4 \mathrm{~km}$ west of the urban settlement of Myadel, among the villages Charovki, Pasynki, Mikoltsy, Gatovichi, Zanaroch, at an altitude of $165 \mathrm{~m}$ above sea level. It is in the Naroch cluster of Lakes and in Naroch National Park.

Lake Naroch is divided into two subbasins by the peninsula Nanosy: Maly (Small) Subbasin, situated in the north-west of the Lake, and Bolshoi (Big) Subbasin - in the south-east. There is an island area of 6.2 hectares at the north-east Lake shore, declared a natural monument. The slopes of the hollow in the north and northeast are $45-50 \mathrm{~m}$ high, formed by the spurs of the Sventsyansk ridges. In the south the lower South-Naroch ridge adjoins the Lake. The shores are low, sandy in the main, steep and abrasive in some places, 2-11 m high, marshy, peat in the south-east (The Blue Book..., 1994). The bathymetric map of Lake Naroch is presented in Fig. 1.

Two terraces are well determined at an altitude of 1.5 and $4.5 \mathrm{~m}$ above the surface. The low shores predominate in the eastern part of the Lake, and in the north-west and west the big parts are represented by the accumulative shores with clean sandy beaches. Almost everywhere, except for the areas of the northern shore the littoral zone with flat inclined surface occupies the wide shore stretch. It is $200 \mathrm{~m}$ wide in the north-west, and as much as $300 \mathrm{~m}$ at the south-eastern shore. The isobaths of $2 \mathrm{~m}$ limits $14 \%$ of the water-table area.

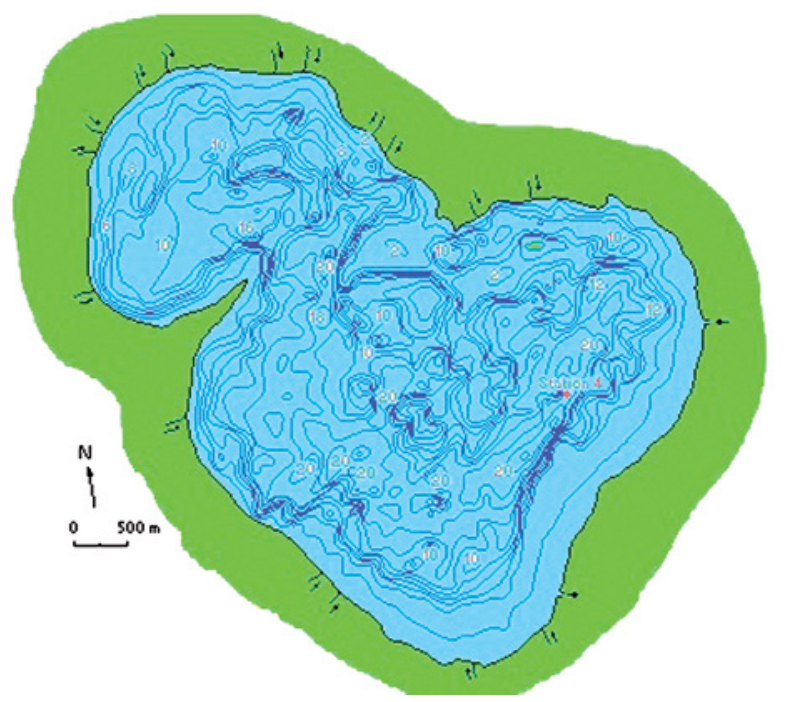

Fig. 1. The bathymetric map of Lake Naroch.
The sloping shallow zone with the depth as much as $5 \mathrm{~m}$ occupies about $30 \%$ of the area. Such an enormous littoral overgrown with the thick cover of water plants plays an important part in the protection of the Lake from polluting substances of the catchment area (Water Resources... 2012).

The area of the Lake water table is $79.62 \mathrm{~km}^{2}$. Its average depth is $8.9 \mathrm{~m}$, the deepest place is in the south-east in the Gatovsk Pits and it is $24.8 \mathrm{~m}$. The width of the Lake is $9.8 \mathrm{~km}$, the length of the longest diameter is $12.8 \mathrm{~km}$, the total shore line is $40 \mathrm{~km}$. About $710 \mathrm{~m}^{3}$ of water is accumulated in Naroch. The lake watershed is $199 \mathrm{~km}^{2}$ (IvanovSmolensky 2013).

Hydrologically Lake Naroch is connected to to the number of oblong ponds. Water enters there from Lake Myaastro through a short duct Skema. Myastro is connected with Batorino by the duct Batorinsky Stream. Besides, Naroch takes water from 17 brooks, mainly from the high hillside. The gutter from the Lake runs down the river Naroch, that flowing out in the south-east falls into the river Viliya - the right tributary of the Neman. A small quantity of specific catchment is expressed in the character of the Lake water balance. During each hydrological year 83.6 million $\mathrm{m}^{3}$ of water flow into Lake Naroch: 30.7 million $\mathrm{m}^{3}$ (about $30 \%$ ) come with the surface drain, the Lake gets more than 52 million $\mathrm{m}^{3}$ (60\%) with atmospheric precipitation falling on the water table. In the expenditure part of the water balance the drain on the River Naroch (56\%) and evaporation from the water surface predominate. As a result the water balance of Naroch is positive because atmospheric precipitation exceeds evaporation, what characterizes the climate of the humid zone. The large area and volume of the Lake water point to a slow process of water exchange. The entire volume of water is replaced every 10 years.

\section{Method}

When examining fluctuations of the Lake level from a plane (increment of the level) an obvious dependence of the level fluctuations on time is out of the question, because initial data on a plane are a large number of dots (Kozhevinkova, Shveykina 2014). For this number of dots a selective regression can be made, showing a measure of scatter of experimental points around a certain 
function $g(x)$, called a regression. More often a measure of scatter $Q(g)$ for uninterrupted on a given prescribed segment of the function $g(x)$ is defined by the formula:

where:

$$
Q(g)=\sum_{j=1}^{n}\left(y_{j}-g\left(x_{j}\right)\right)^{2}
$$

$y$ - ordinate,

$x$ - time of experimental observations.

Veyershtrass Law says, that any uninterrupted on the final segment function can be approximated by an algebraic polynomial with any prescribed accuracy; therefore it can be used for analyzing of water level fluctuations using the parameter model of mode (Kozhevnikova, Shveykina 2014, Ozaki 1981).

where:

$$
\Delta H=\Phi(H)+\gamma(t),
$$

$H$ - water body level,

$\Delta H$ - water body level increments,

$\gamma(t)$ - random disturbed force,

$\Phi(H)$ - algebraic polynomial, named autonomous (independent on time) regression.

An independent variable value (time) is not obviously in the autonomous equation or the system of the autonomous equations, what means, that the law of fluctuations of unknown functions, described by the autonomous equation or the system of the autonomous equations is not changed in due course. Therefore the received solution of this equation gives an opportunity to conduct modeling of water level beyond the examining period of time.

For conducting calculations and the following modeling initial data of observations are normalized with the help of the transformation:

where:

$$
Z(t)=\frac{2 H(t)-H_{\max }-H_{\min }}{H_{\max }-H_{\min }},
$$

$Z(t)$ - normalized quantity of water body level,

$H(t)$ - initial level at the moment of time $t=1, \ldots, N$,

$H_{\max }=\max _{1 \leqslant \leqslant \mathrm{~N}} H(t)$ - maximum level,

$H_{\min }=\min _{1 \leq \leqslant \leq N} H(t)$ - minimuml level.

The method of parametric regression is based on using the following linear (relatively to parameters) differential difference equation:

where:

$$
Z(t+1)-Z(t)=\Phi(Z(t))+\gamma^{(\mathrm{k})}(t)
$$

$\gamma^{(k)}(t)$ - a residual sequence of a regression model of order $k$,
$\Phi(Z(t))$ - calculated from the ratio:

$$
\Phi(Z(t))=\sum_{i=0}^{k} a_{i} Z^{i}(t) .
$$

Let's assume that this sequence has a constant expected value and dispersion and its values are not correlated. Estimations of parameters ai are calculated under condition of minimum of the function $Q$ by least squares method.

$$
Q\left(a_{0}, a_{1}, \ldots, a_{k}\right)=\sum_{t=1}^{N-1}\left[Z(t+1)-Z(t)-\sum_{i=0}^{k} a_{i} Z^{i}(t)\right]^{2},
$$

where:

$k$ - a degree of a polynomial,

$N$ - a number of statistics of observations.

The function $Q\left(a_{0^{\prime}} a_{1}, \ldots, a_{k}\right)$ achieves minimum at the points, where derivatives of corresponding variables are turned into zero. These equations are linear relatively to parameters and are solved in a usual way. The degree of a polynomial $k$ is selected under condition of stabilization of the sum of the residual sequence squares.

In solving the equation $\Phi(Z(t))=0$ get equilibrium positions of a level for normalized data and corresponding them level equilibrium absolute positions under consideration of a derivative at given points mean stable (symbol "-") or unstable (symbol "+") (Pontryagin 1965). For clear proof of movement of an ideal point under the influence of a random stimulated force, they consider the potential:

$$
U(H)=-\int \Phi(H) d H
$$

Potentials minimums correspond to stable equilibrium conditions and maximums unstable position.

For modeling of the trajectory a residual sequence is worked on. If the considering function $Y(t)$ is the sum of the periodic function $f_{p}(t)$ with the period $P_{0}$ and noise $E(t)$, the type of the periodic function $f_{p}(t)$ is revealed under putting the segments of series $Y_{k}$ with the length $P_{0}$ on each other. For that it is necessary to discontinue time series with the period $P_{0}$ and consider the phase diagram of this period. The phase diagram is a dependence $Y_{k}$ on $X_{k^{\prime}}$ where abscissa $X_{k}$ is calculated by the following equation (Terebizh 1992)

where:

$$
X_{k}=f r\left(\frac{t_{k}-t_{*}}{P_{0}}\right), k=1, \ldots N,
$$

$f r(z)$ - fractional part of number $z$,

$t_{k}$ - time moments of observation,

$T$ - random sample time moment. 


\section{Data}

The research is based on the materials of the observations of Hydrometeorology Department of Ministry of natural resources and environment protection of the Republic of Belarus average annual indices of water levels in Lake Naroch within 55-year interval (from 1956 till 2010). In order to analyze the number of the data of the observation the graph of water level fluctuations in Lake Naroch was built within the studied interval, represented in Fig. 2.

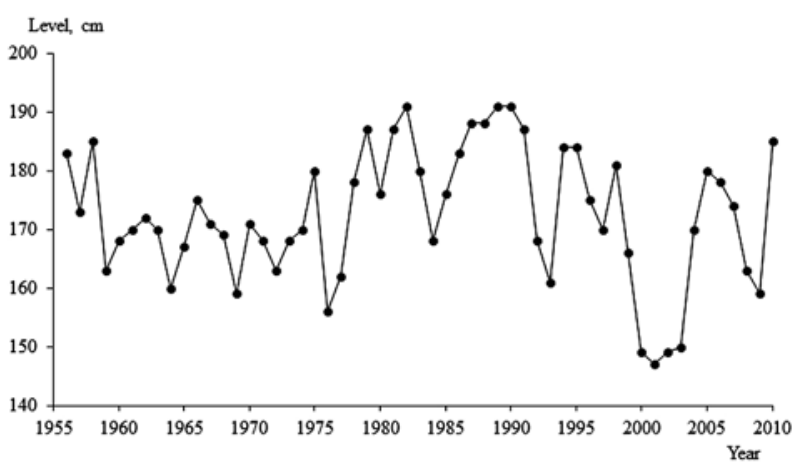

Fig. 2. The fluctuations of the level in Lake Naroch, 1956-2010.

The fluctuations of the water level during the whole year are as much as 40 , sometimes $70 \mathrm{~cm}$. In flood-time the area of the Lake is increased by $2 \% .21 \%$ of the Lake area is overgrown. The subbasin Maly has been overgrown most of all. The width of the overgrown stripe is as much as $2 \mathrm{~km}$ in the north-eastern part, on the subbasin Bolshoifrom $5 \mathrm{~m}$ up to $350 \mathrm{~m}$. Reed, bulrush grow at a depth of 1.5-2 m, they cover less than $3 \%$ of the Lake area, submarine plants, among which stoneworth algae predominate, extend to the depth of $7.5 \mathrm{~m}$, and occupy $18 \%$ of the Lake bottom area (The Blue Book... 1994, Water Resources... 2012, Ivanov-Smolensky 2013, Volchak, Kirvel 2013).

\section{Results}

In order to model the level fluctuations to avoid mistakes when rounding in calculating the source data were normalized with the help of the transformation (3). Using the models (4)-(5) for the normalized data the sums of squares of the residual sequence $\gamma^{(k)}(t)$ for the degree of the polynomial $k$, equal numbers from 3 to 10 inclusive

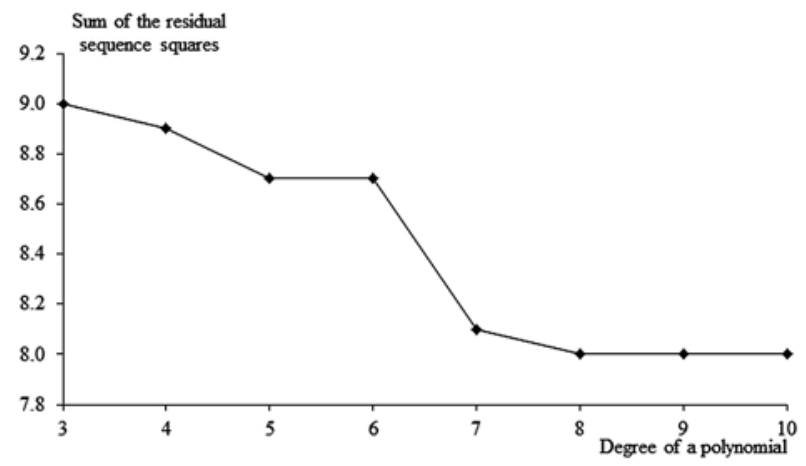

Fig. 3. Dependence of the sum of the squares of the residual sequence on the degree of a polynomial.

were calculated. The given results testify the stabilization of the residual sum of the squares of the normalized data become when $k=8$, consequently further increasing of the regression order is not demanded (Fig. 3).

Further by the least square method the function $\Phi(Z(t))$ was calculated, describing the fluctuations of the normalized data of the observations and represented in the form of the polynomial regression of the $8^{\text {th }}$ degree:

$$
\begin{gathered}
\Phi(Z(t))=-9.8234 Z^{8}(t)-9.5248 Z^{7}(t)+ \\
+20.3185 Z^{6}(t)-1763.99 Z^{5}(t)-13.8939 Z^{4}(t)-\quad(9) \\
-8.3926 Z^{3}(t)+3.3150 Z^{2}(t)+0.1504 Z^{1}(t)-0.0134 .
\end{gathered}
$$

The equilibrium positions of the level are the roots of the equation $\Phi(Z(t))=0$ and take the values $Z 1=-0.082, Z 2=0.049, Z 3=0.349$ for normalized data, what corresponds three values of the level $H 1=167.2 \mathrm{~m}, H 2=170,1 \mathrm{~m}, H 3=176.7 \mathrm{~m}$, being the position of balance (Fig. 4).

Using the equation (7) the level potential of Lake Naroch has been investigated (Fig. 5). The potential points of extremes coincide with the roots of the equation $\Phi(Z(t))=0$. In that case two minimums $H 1=167.2 \mathrm{~m}, H 3=176.7 \mathrm{~m}$, (stable equilibrium conditions) and one maximum

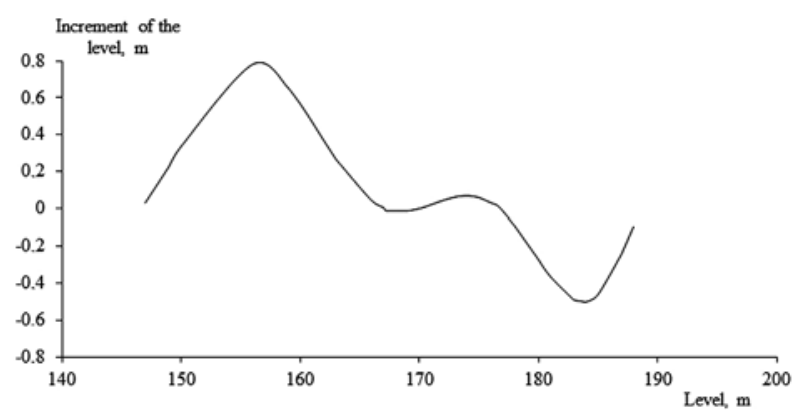

Fig. 4. Polynomial regression of the 8th order on an absolute scale. 


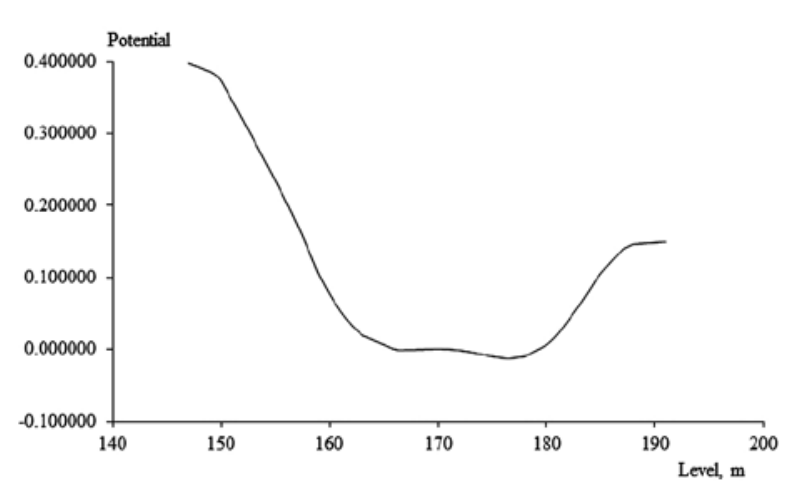

Fig. 5. Potential of the regression of the 8th order.

H2=170.1 m (unstable level) are typical for Lake Naroch.

To model the trajectory of the level fluctuations the residual sequence was studied. The period of the residual sequence was determined with the use of spectral time analysis that is based on the calculation of the spectra of the variation on moving time periods (Ikonnikov et al. 2003). For Lake Naroch level 2 year cycle was determined, what is taken as a basis for making a phase diagram on the base of the ratio (8), represented in Figure 6.

Let's assume, that the phase diagram of the residual sequence has a characteristic sinusoidal form for seasonal oscillations, then it can be represented in the following way

$\gamma^{(8)}(t)=A_{0}+A_{1} \sin 4 \pi t+A_{2} \cos 4 \pi t+\varepsilon(t), t=1,2, \ldots N,(10)$

where:

$\varepsilon(t)$ - sequence of independent equally distributed random quantities.

The values of unknown parameters of the equation (10) were received by least squares method and have the following values: $\mathrm{A}_{0}=0$, $\mathrm{A}_{1}=0.03418, \mathrm{~A}_{2}=0.10471$. After extracting the periodic component from the residual sequence the parameters of the sequence $\varepsilon(t)$ were calculated, they have the following values: mean $M_{k}=0$ and standard deviation $\sqrt{D}_{k}=0.3805$.

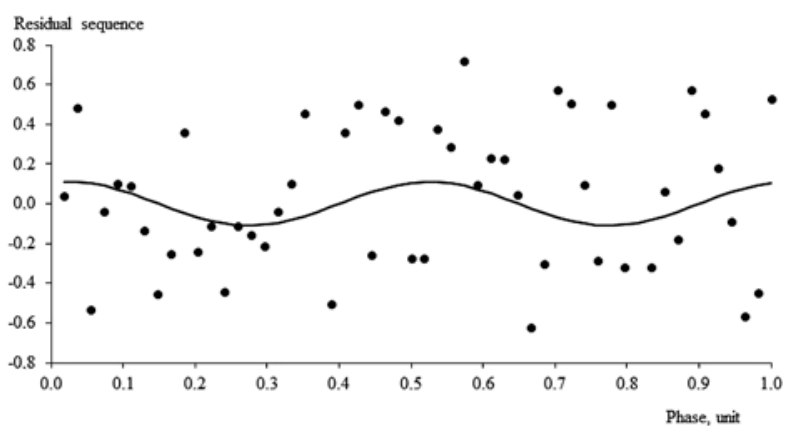

Fig. 6. Phase diagram of the residual sequence.
In order to model the trajectory of the level in Lake Naroch the equation (9) is transformed into the following equation:

$$
\begin{gathered}
Z(t+1)=-9.8234 Z^{8}(t)-9.5248 Z^{7}(t)+20.3185 Z^{6}(t)- \\
-1763.99 Z^{5}(t)-13.8939 Z^{4}(t)-8.3926 Z^{3}(t)+ \\
+3.3150 Z^{2}(t)+0.1504 Z^{1}(t)-0.0134+ \\
+A_{0}+A_{1} \sin 4 \pi t+A_{2} \cos 4 \pi t+\varepsilon(t),
\end{gathered}
$$

where:

$\varepsilon(t)$ - residual sequence, having Gaussian distribution with the parameters $\mathrm{N}(0 ; 0.3805)$.

In Figure 7 there is a trajectory, having modeled with the help of the autonomous differentialdifference equation and periodic component. The trajectory demonstrates the transitions from upper level to lower one, sharp or gradual rises and falls. Such a trajectory makes it possible to get a probable prediction by method of mathematical modeling-making quite a great number of trajectories and calculating on there base probabilities of reaching that or either level.

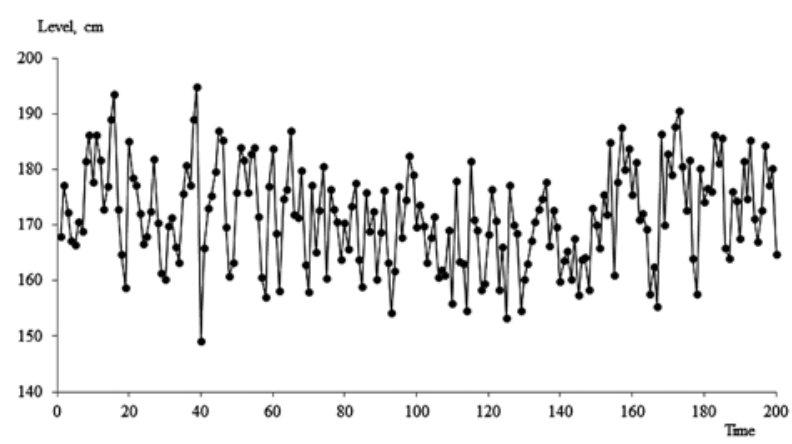

Fig. 7. Modeling of the trajectory of the level fluctuations in Lake Naroch.

Modeling of the trajectory 200 years long using the formula (11) showed that 2 values are over the limits of the maximum annual level equal $191 \mathrm{~cm}$, which is $1 \%$. It allows saying that the probability of exceeding of maximum annual level in Lake Naroch is improbable.

\section{Conclusion}

As a result of the conducted investigations of the level fluctuations in Lake Naroch the initial data are divided into 3 components:

(a) a polynomial regression that makes it possible to find out an independent on time Law of trajectory,

(b) a periodic component of sinusoidal type, and 
(c) a residual sequence of independent random quantities.

Modeling of the trajectory fluctuations is based on the deterministic part, consisting of the regression of the $8^{\text {th }}$ order and periodic component, and also the random part, consisting of independent equally distributed quantities.

Using this model it can be modeled the trajectory of the level fluctuations in Lake Naroch. The modeled trajectory by 200 years long demonstrated the probability of exceeding of maximum annual level that is equal 1 per cent.

The proposed method can be used for modeling and forecasting the level of other lakes. But equation (11) applies only to Lake Naroch; to other lakes the additional studies are needed.

\section{References}

Aivazyan S.A., Enyukov I.S., Meshalkin L.D., 1985. Applied Statistics. Investigation of Dependences: Finances and Statictics, Moscow.

Ikonnikov V.F, Lishtvan I.I., Loginov V.F., 2003. Use of Nature: Collection of Scientific Works. Minsk, Iss. 9: 25-33.

Ivanov-Smolensky V.G., 2013. AU Lakes of Belarus. Riftur Print, Minsk.

Kozhevnikova I.A., Shveykina V.I., 2014. Modelling of the Level Fluctuations of Lake Kinneret. Water Resources 41(1): 565-572.

Loginov V.F., 2007. Spectral-time Analysis of the Level Mode of the Lakes and Fluctuations of Consumption of Large Rivers in Belarus. Minsk.

Ozaki T., 1981, Nonlinear time series models for non-linear random values. Journal of Applied Probability 18: 443-451.

Pontryagin L.S., 1965. Ordinary Differential Equations. Science, Moscow.

Terebizh V.Yu., 1992. Analysis of Time Series in Astrophysics. Science, Moscow.

The Blue Book of Belarus, 1994. Encyclopaedia/Belarus. Minsk. Volchak A., Kirvel I., 2013. Lake water level variations in Belarus. Limnological Review 13(2): 115-126.

Water Resources of the National Park "Narochansky", 2012. Reference Book. Riftur Print, Minsk. 